Research Article

\title{
Platinum Nanoflower-Modified Electrode as a Sensitive Sensor for Simultaneous Detection of Lead and Cadmium at Trace Levels
}

\author{
Thi Lieu Nguyen $\mathbb{D}^{1,}{ }^{1,2}$ Van Hoang Cao, ${ }^{2}$ Thi Hai Yen Pham, ${ }^{3}$ and Truong Giang Le $\mathbb{D}^{1,3}$ \\ ${ }^{1}$ Graduate University of Science and Technology, Vietnam Academy of Science and Technology, 18-Hoang Quoc Viet, \\ Hanoi, Vietnam \\ ${ }^{2}$ Department of Chemistry, Quy Nhon University, 170-An Duong Vuong, Quy Nhon, Binh Dinh, Vietnam \\ ${ }^{3}$ Institute of Chemistry, Vietnam Academy of Science and Technology, 18-Hoang Quoc Viet, Hanoi, Vietnam \\ Correspondence should be addressed to Thi Lieu Nguyen; nguyenthilieu@qnu.edu.vn and Truong Giang Le; \\ hoasinhmoitruong.vast@gmail.com
}

Received 1 March 2019; Revised 7 May 2019; Accepted 29 May 2019; Published 12 June 2019

Guest Editor: Ajit Kumar Sharma

Copyright ( 2019 Thi Lieu Nguyen et al. This is an open access article distributed under the Creative Commons Attribution License, which permits unrestricted use, distribution, and reproduction in any medium, provided the original work is properly cited.

\begin{abstract}
We introduce the fabrication and electrochemical application of platinum nanoflower-modified glassy carbon electrode (PtNFs/ GCE) for the trace level determination of lead and cadmium using differential pulse anodic stripping voltammetry (DPASV). The modified electrodes have been characterized by EDX, XRD, SEM, and AFM techniques to confirm chemical and physical properties. The effect of potential electrodeposition on the properties of the electrode was investigated. At $-0.2 \mathrm{~V}$ of potential, platinum developed with a nanoflower shape and dispersed densely all over the glassy carbon surface. In this condition, the highest of lead and cadmium electrochemical signals was clearly observed. The sensor showed wide linearity in the concentration range of $1-100 \mu \mathrm{g} \cdot \mathrm{L}^{-1}$ with detection limits of $0.408 \mu \mathrm{g} \cdot \mathrm{L}^{-1}$ and $0.453 \mu \mathrm{g} \cdot \mathrm{L}^{-1}$ for lead and cadmium ions, respectively. The produced electrodes have good reproducibility with relative standard deviations of $4.65 \%$ for lead and $4.36 \%$ for cadmium ions. The results demonstrate that this simple, stable, and sensitive sensor is suitable for the simultaneous electrochemical determination of $\mathrm{Pb}^{2+}$ and $\mathrm{Cd}^{2+}$ at trace levels.
\end{abstract}

\section{Introduction}

One of the crucial factors leading to worldwide environmental pollution is the presence of heavy metal ions. Among heavy metals, cadmium is one of the most toxic heavy metals found in some surface and subsurface waters. A number of acute and chronic illnesses such as emphysema, hypertension, and skeletal malformation in the fetus have been attributed to the harmful properties of cadmium [1]. Another frequently encountered toxic contaminant in the environment is lead due to its application for car batteries, paints, and gasoline [2]. In detail, lead can disturb the metabolism of calcium and other critical nutrients by competing for binding sites [3]. Lead poisoning causes a variety of symptoms such as digestive, neurological, cardiac, and abdominal pain [4]. Several critical health problems have been attributed to lead and most of the effects are observed in children, infants, and unborn individuals [5]. The significant environmental and biological damages caused by cadmium and lead call for rapid, sensitive, and simple analytical methods for their detection and monitoring.

Among analytical methods, electrochemical methods are the most efficient techniques for the determination of heavy metal ions because of their simple operation, low cost, high sensitivity, and capability to analyze elemental speciation. The efficiency of electrochemical analysis is strongly affected by the properties of the working electrode. Platinum has been commonly used as the electrode material. The major advantages of platinum in electrochemistry are chemical inertness, stability, easy fabrication, high conductivity, high reactivity, low background current [6], and high catalytic activity for a wide variety of reactions. The catalytic activity 
of platinum depends on the size and orientation of platinum particles [7-9]; platinum nanoparticles (PtNPs) are over 100 times more active than microsized platinum powder and 1000 times more active than macrosized platinum [10]. Besides the high catalytic activity, nanoplatinum shows the fast electron exchange and the high ratio of surface area to volume [11]. Thus, the nanostructured electrode could help significantly increase the sensitivity in the analysis at trace levels.

So far, platinum nanostructured electrodes have been used for substrate modification and applied in detection of various organic compounds such as glucose [12], cholesterol [13], ascorbic acid [14], dopamine, uric acid [15], and granisetron [16]. In these research studies, the electrochemical signals of targets observed on the modified electrodes increased dramatically compared with those observed on the substrate that demonstrates the faster electron transfer and a larger electroactive surface of the nanostructured electrodes. However, there are a few authors studying Pt nanostructured electrodes for heavy-metal determination. In [17], Yoon et al. blended Pt nanoparticles with carbon powder and organic binder for electrode manufacturing to investigate the catalytic activity of platinum nanoparticles in the copper analysis. This modified electrode improved the copper peak current which is three times higher than that measured on the nonmodified electrode. Besides, almost fabricated Pt nanoelectrode for determination of organic compounds and heavy metals were at the construction of the sphere [17] or cube [14]. The platinum nanothorn with sharp tips and edges was electrochemical prepared; however, this material was used as a platform in surface-enhanced Raman scattering (SERS) measurement with high activity [18]. Besides, Pt nanoflowers, that is, nanostructures of $\mathrm{Pt}$ with flower-like shape, were prepared by using different methods such as chemical method $[19,20]$ and electrochemical method with cyclic voltammetric technique [12]. These electrodes exhibited a high electrochemically active surface area, thus leading to a high electrocatalytic activity.

In the present work, we developed a nanoflower-shaped platinum on a glassy carbon electrode by a one-step electrochemical deposition method and used it as a sensing probe in the simultaneous measurement of $\mathrm{Pb}^{2+}$ and $\mathrm{Cd}^{2+}$ ions at trace levels. The modified electrode was characterized by cyclic voltammetry (CV), field-emission scanning electron microscope (FE-SEM), energy dispersive X-ray (EDX), atomic force microscopy (AFM), and X-ray diffraction (XRD). The electrochemical behavior of lead and cadmium has been investigated with a sensitive, fast, and simple different pulse anodic stripping voltammetry (DPASV) method. In addition, the enhancement of the sensibility in $\mathrm{Pb}$ and $\mathrm{Cd}$ analysis has been evaluated when using the fabricated platinum nanoflowers electrodes.

\section{Experimental}

2.1. Reagents. All reagents necessary for the construction of $\mathrm{Pt}$ nanoflowers and subsequent measurements, hexachloroplatinic (IV) acid hexahydrate, potassium hexacyanoferrate (III), sodium dihydrogen phosphate, disodium hydrogen phosphate, potassium chloride, sodium acetate, sulfuric acid, hydrochloric acid, acetic acid, lead stock solution (1000 ppm), and cadmium stock solution (1000 ppm), were purchased from Merck (KGaA, 64271 Darmstadt, Germany).

2.2. Apparatus. All electrochemical measurements were performed at room temperature. A three-electrode system with platinum nanoflower-modified glassy carbon electrode (PtNFs/GCE) as a working electrode, an $\mathrm{Ag} /$ $\mathrm{AgCl}$ reference electrode, and a platinum wire counter electrode were used to perform electrochemical measurements. The three-electrode system was connected to a custom-made multifunction potentiostat/galvanostat manufactured at the Vietnam Academy of Science and Technology (Hanoi, Vietnam). It was equipped with 12-byte analog-digital, digital-analog converters (ADC-DAC) with two operational amplifiers, which can provide ultrasensitive measurements with current resolution down to $0.008 \mathrm{nA}$. A field-emission scanning electron microscope (FE-SEM, S-4800, Hitachi Company, Japan) was employed to evaluate the morphologies of the PtNFs/GCE. The crystal phase was determined by D8 ADVANCE, Bruker, using $\mathrm{CuK}_{\alpha}(\lambda=1.54060 \mathrm{~nm})$ and scanning degree $2 \theta=20-70^{\circ}$. Energy dispersive $\mathrm{X}$-ray spectroscopy (EDX) was performed with a JSM-6510LV, JEOL Ltd. Company, Japan. Atomic force microscopy (AFM) was performed with a Solver PRO SPM, NT-MDT Company, Russian.

2.3. Preparation of Modified Electrode. The glassy carbon electrode $(d=3.0 \mathrm{~mm})$ was washed with water and ethanol, then polished with a water slurry of $0.05 \mu \mathrm{m}$ size of alumina powder to get a smooth and shiny surface, then electrodes were rinsed with double-distilled water and placed in an ultrasonic bath for a few minutes to remove any residual polishing material on the electrode surface, and then the electrode was dried at room temperature. The electrodeposition of platinum nanoparticles on the bare glassy carbon electrode was carried out in $0.1 \mathrm{M} \cdot \mathrm{H}_{2} \mathrm{SO}_{4}$ solution containing $1.0 \mathrm{mM} \cdot \mathrm{H}_{2} \mathrm{PtCl}_{6}$. The effect of deposition potential $\left(E_{\mathrm{Pt}}\right)$ on properties of the fabricated Pt layer was investigated. The effect of deposition time $\left(t_{\mathrm{Pt}}\right)$ was evaluated in our previous study and herein we used the optimal value of $t_{\mathrm{Pt}}$, that is, $150 \mathrm{~s}$ for further experiences. Following that, the Pt/GCE was gently cleaned with distilled water before use.

2.4. Electrochemical Measurements. The electrochemical measurements of the proposed sensor were carried out at room temperature $\left(25 \pm 1^{\circ} \mathrm{C}\right)$ by the cyclic voltammetry $(\mathrm{CV})$ and different pulse anodic stripping voltammetry (DPASV) methods. The electrochemical properties of the PtNFs/GCE were investigated by the cyclic voltammetric (CV) method in $0.5 \mathrm{M} \cdot \mathrm{H}_{2} \mathrm{SO}_{4}$ solution from $-0.1 \mathrm{~V}$ to $1.4 \mathrm{~V}$ and solution of $0.2 \mathrm{M}$.PBS pH 7 containing $5 \mathrm{mM}\left[\mathrm{Fe}(\mathrm{CN})_{6}\right]^{3-}$ from $-0.3 \mathrm{~V}$ to $0.8 \mathrm{~V}$ at a scan rate of $0.1 \mathrm{~V} \cdot \mathrm{s}^{-1}$. The DPASV studies were carried out with preconcentration time $120 \mathrm{~s}$, pulse amplitude 
$0.060 \mathrm{~V}$, pulse time $0.050 \mathrm{~s}$, step potential $0.007 \mathrm{~V}$, step time $0.03 \mathrm{~s}$, and sweep rate $0.25 \mathrm{~V} \cdot \mathrm{s}^{-1}$. The $\mathrm{Pb}^{2+}$ and $\mathrm{Cd}^{2+}$ ions were stripped of the electrode surface in the scan range -1.2 to $0.2 \mathrm{~V}$, and the peak currents were measured.

\section{Results and Discussion}

3.1. Formation and Properties of PtNFs/GCE. Platinum nanoflowers (PtNFs) were electrochemically deposited on GC by chronoamperometry in $1.0 \mathrm{mM} \cdot \mathrm{H}_{2} \mathrm{PtCl}_{6} / 0.1 \mathrm{M} \cdot \mathrm{H}_{2} \mathrm{SO}_{4}$ solution. An overview of the electrochemical behavior of this system is provided in Figure 1(a), which is a current-potential curve obtained from a cyclic voltammetric experiment at a polished GC electrode in $0.1 \mathrm{M} \cdot \mathrm{H}_{2} \mathrm{SO}_{4}$ and in $0.1 \mathrm{M} \cdot \mathrm{H}_{2} \mathrm{SO}_{4}$ solution containing $10.0 \mathrm{mM} \cdot \mathrm{H}_{2} \mathrm{PtCl}_{6}$. This wave exhibits three potential regions: the hydrogen region (from -0.2 to $+0.15 \mathrm{~V}$ ) corresponds the adsorption/desorption of hydrogen with different energies, a broad oxidation peak for the Pt-oxide formation (commences at $0.7 \mathrm{~V}$ and extends up to $1.2 \mathrm{~V}$ ), and a single reduction peak at $0.5 \mathrm{~V}$ corresponding to the reduction of $\mathrm{Pt}(\mathrm{IV})$ to $\mathrm{Pt}(0)$ on the electrode surface. The result is in agreement with previous studies [21-23]. Therefore, in order to deposit Pt onto the GCE by chronoamperometry, the applied potential must be lower than $0.3 \mathrm{~V}$.

Typical CV measured in $0.5 \mathrm{M} \cdot \mathrm{H}_{2} \mathrm{SO}_{4}$ solution on the prepared Pt electrode is presented (Figure 1(b)). After the oxidation of $\mathrm{Pt}$ in the scanning at the anodic direction from -0.1 to $1.5 \mathrm{~V}$, in the reverse direction, the clear cathodic peak is observed at $0.5 \mathrm{~V}$ presented for the reduction of $\mathrm{Pt}$ (IV) on GC. These observations are in agreement with the data of other authors $[23,24]$. This means that Pt had been deposited on glassy carbon platforms at the studied potential.

3.2. Characterization of Platinum Nanoparticles. In order to study the surface morphology, chemical characterization, and structure of the platinum particles, the field-emission scanning electron microscopy, X-ray diffraction, energy dispersive X-ray spectroscopy, and atomic force microscopy techniques were used in the next experiment.

3.2.1. EDX Study. The presence of Pt nanoparticles on the glassy carbon electrode surface is verified by the EDX analysis (Figure 2). The spectrum contained two peaks which were assigned to $\mathrm{C}$, Pt.

The major peaks are around $0.28,2.10 \mathrm{keV}$, which correspond to the binding energy of $\mathrm{C}$, Pt. This also confirms that no other impurities have been identified. The weight ratios of prepared $\mathrm{Pt}$ on the electrodes increase as $E_{\mathrm{Pt}}$ changes from $0.2 \mathrm{~V}$ to $-0.3 \mathrm{~V}$ then decrease at $-0.5 \mathrm{~V}$. This can be concluded that the amount of platinum deposited on the GCE strongly depends on the electrodeposition potential. These data show that platinum was successfully deposited on the surface of the glassy carbon with the highest amount at the applied potential of $-0.3 \mathrm{~V}$.

3.2.2. XRD Study. Figure 3 shows the $\mathrm{X}$-ray diffraction patterns of platinum nanoparticles deposited on the glassy carbon electrode. There were three well-defined characteristic diffraction peaks at $39.9^{\circ}, 46.2^{\circ}$, and $67.5^{\circ}$ respectively, indexed to reflections from (111), (200), and (220) planes of the face-centered cubic $(\mathrm{fcc})$ crystal structure of metallic platinum. This result evidently exhibits that Pt exists on the GCE surface. The result is in agreement with previous studies [25-27].

3.2.3. SEM Study. The surface morphology of the Pt/GCE was investigated by microscopic imaging analysis. Figure 4 shows the typical SEM images of the GCE (Figure 4(a)) and Pt layer electrodeposited on the GCE under different electrodeposition potentials. The size of individual PtNF piece rises up to exceed the nanoscale. According to the SEM images, Pt was formed separately in nanoparticles shape at the deposition potential of $0.2 \mathrm{~V}$ and $0.0 \mathrm{~V}$ (Figures 4(b) and 4(c)) and in nanoflowers shape at the deposition potential of $-0.2 \mathrm{~V}$ and $-0.3 \mathrm{~V}$ (Figures $4(\mathrm{~d}$ ) and $4(\mathrm{e}))$, and at the deposition potential of $-0.5 \mathrm{~V}, \mathrm{Pt}$ developed into a film on the GCE (Figure 4(f)). This can be explained that at a negative potential, both hydrogen bubble release and Pt formation occur simultaneously, which resulted in the flower shape of $\mathrm{Pt}$, while a positive potential represented the potential range at which only $\mathrm{Pt}$ formation occurred. At the deposition potential of $-0.3 \mathrm{~V}$, the flower-shaped form is still maintained; however, large Pt clusters are observed due to the formation of Pt particles between flowers. It is observed in Figure 4(e) that there are some defects at which no Pt occupied resulting from the attachment of large $\mathrm{H}_{2}$ bubble at those sites. At the deposition potential of $-0.5 \mathrm{~V}$, the Pt flower pieces developed slapping whereby they aggregated into a film, they had not been single, free flower-shaped structures at nanoscale any longer. In addition, the stronger hydrogen bubble release at that potential should significantly prevent the formation of $\mathrm{Pt}$ on the electrode surface; thus, many sites of glassy carbon surface (black spots) that have no Pt occupying can be seen in Figure 4(f). This structure would lead to a decrease of electrochemically active surface area of an electrode. This result will be reaffirmed in the next section.

3.2.4. AFM Study. The surface morphology of the GCE, platinum nanoparticle-modified GCE with deposition potential of $0.2 \mathrm{~V}$ (Pt0.2/GCE), and $-0.2 \mathrm{~V}(\mathrm{Pt}-0.2 / \mathrm{GCE})$ was examined by atomic force microscopy (AFM). The main goal was to determine and characterize a possible difference between the surface morphologies of the electrodes. A set of typical AFM images obtained for electrode surfaces tested in our study is shown in Figure 5. The images clearly reveal that the electrodes are used in different surface morphology.

The surface of the glassy carbon electrode appears to be smooth, atomically flat terraces (Figure 5(a)). To describe the electrode surface more quantitatively and to provide a quantitative comparison of the surface quality among the tested electrodes, we employed the root-mean-square (RMS) roughness [28]. RMS has been established as a rigorous quantitative measure of the surface roughness, and the 


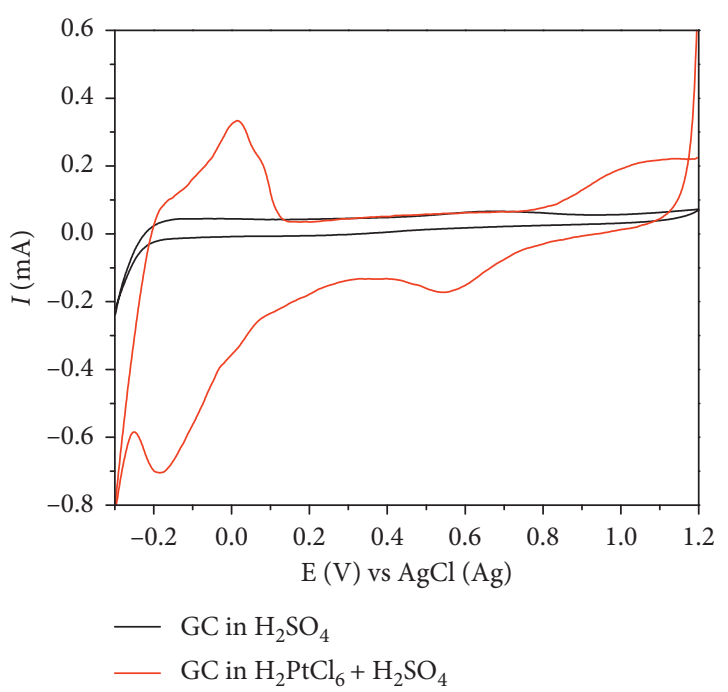

(a)

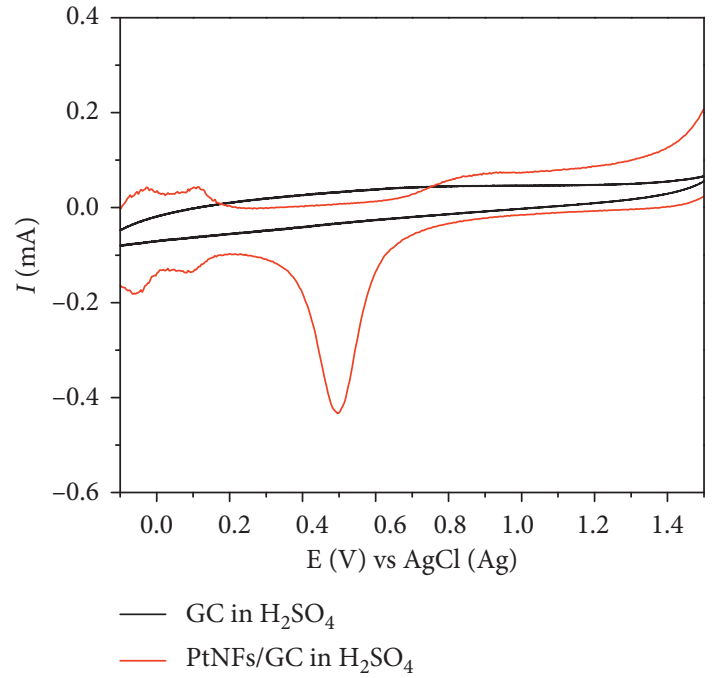

(b)

Figure 1: The cyclic voltammograms of a glassy carbon electrode in $0.1 \mathrm{M} \cdot \mathrm{H}_{2} \mathrm{SO}_{4}$ solution and in $0.1 \mathrm{M} \cdot \mathrm{H}_{2} \mathrm{SO}_{4}$ solution containing $10.0 \mathrm{mM} \cdot \mathrm{H}_{2} \mathrm{PtCl}_{6}$ solution (a); a glassy carbon electrode and $\mathrm{Pt} / \mathrm{GCE}$ in $0.1 \mathrm{M} \cdot \mathrm{H}_{2} \mathrm{SO}_{4}$ solution (b), scanning rate of $0.1 \mathrm{~V} / \mathrm{s}$.

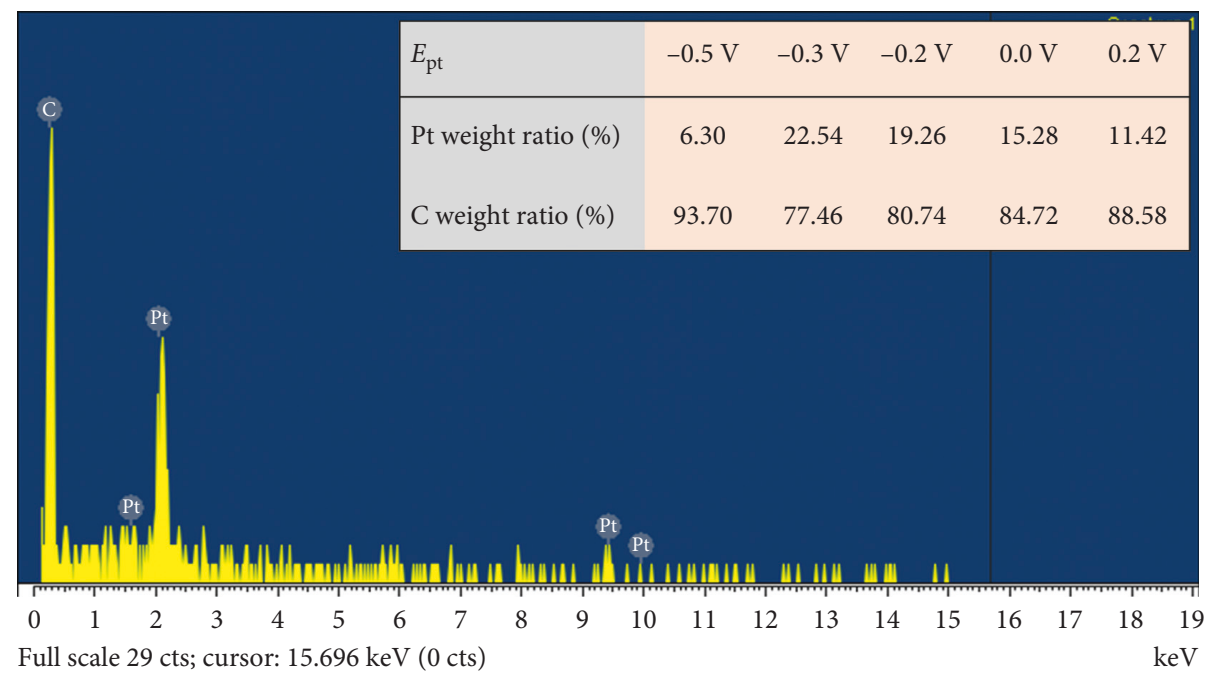

FIgURE 2: EDX spectra for the Pt/GCE prepared at the deposition potential of $-0.3 \mathrm{~V}$ and the weight ratio of Pt element on the GCE at the different deposition potential $\left(E_{\mathrm{Pt}}\right)$ (inset).

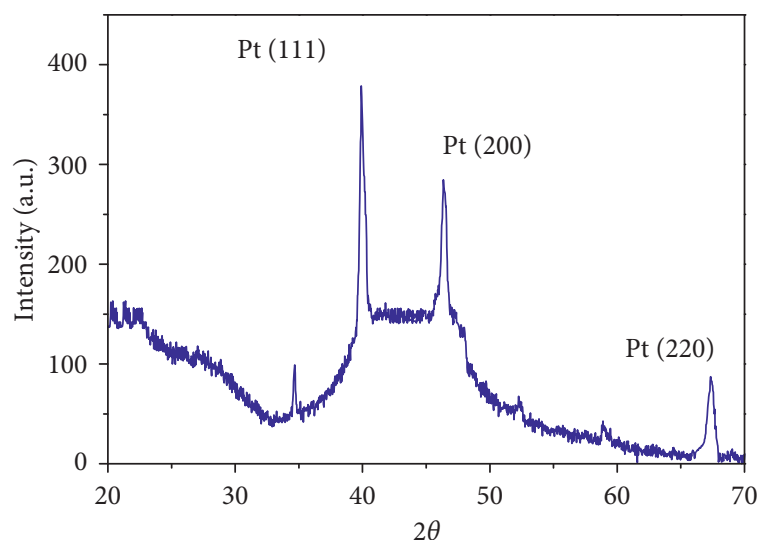

FIGURE 3: The X-ray diffraction pattern of platinum nanoparticles showing the face-centered cubic (fcc) crystal structure. surface quality has often been used for such purpose. Apparently, it is one of the simplest morphology parameters that can be used for the surface quality description. For the GC electrode, we found that the average RMS is $672.82 \mathrm{~nm}$. Contrary to the smooth and homogeneous surface of the GC electrode, the AFM image in Figure 5(b) reveals numerous features distributed all over the $\mathrm{Pt}-0.2 / \mathrm{GC}$ electrode surface. Typical morphology of $\mathrm{Pt}-0.2 / \mathrm{GC}$ electrode surface is shown in Figure 5(c). The AFM images of the electrode surface reveal mainly nodular features. However, they appear to be of a different shape and a lower height than those observed at the $\mathrm{Pt}-0.2 / \mathrm{GC}$ electrode surface. As expected, the $\mathrm{Pt}-0.2 / \mathrm{GC}$ electrode surface possessed a lower RMS value $(730.53 \mathrm{~nm})$ than that of the $\mathrm{Pt}-0.2 / \mathrm{GC}$ electrode surface $(777.09 \mathrm{~nm})$. In comparison with other electrodes, it is obvious that the $\mathrm{Pt}-0.2 / \mathrm{GC}$ electrode surface has the most 

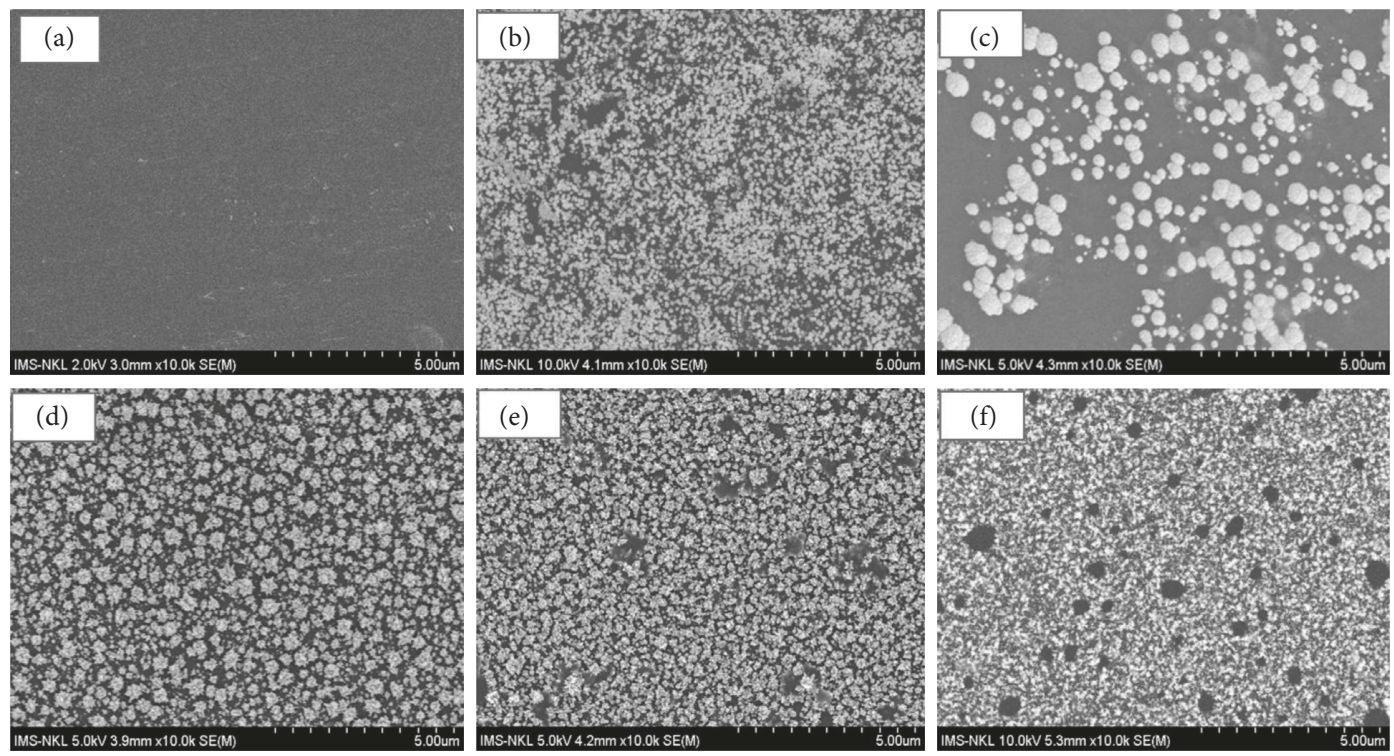

Figure 4: SEM images of GCE (a); PtNFs/GCE deposited at potential of $0.2 \mathrm{~V}$ (b), $0.0 \mathrm{~V}$ (c), $-0.2 \mathrm{~V}$ (d), $-0.3 \mathrm{~V}$ (e), and $-0.5 \mathrm{~V}$ (f). Solution of $0.1 \mathrm{M} \cdot \mathrm{H}_{2} \mathrm{SO}_{4}$ containing $1.0 \mathrm{mM} \cdot \mathrm{H}_{2} \mathrm{PtCl}_{6}$; stirring at $50 \mathrm{rpm}$.
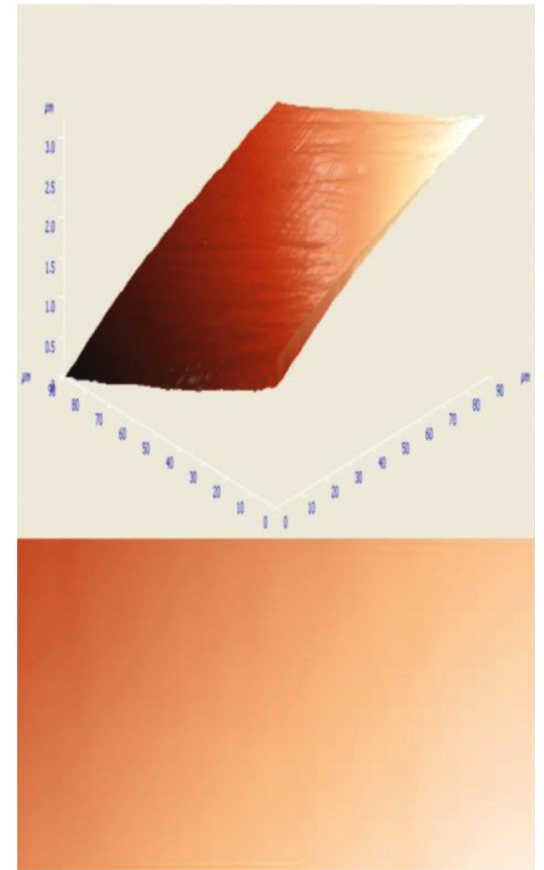

(a)
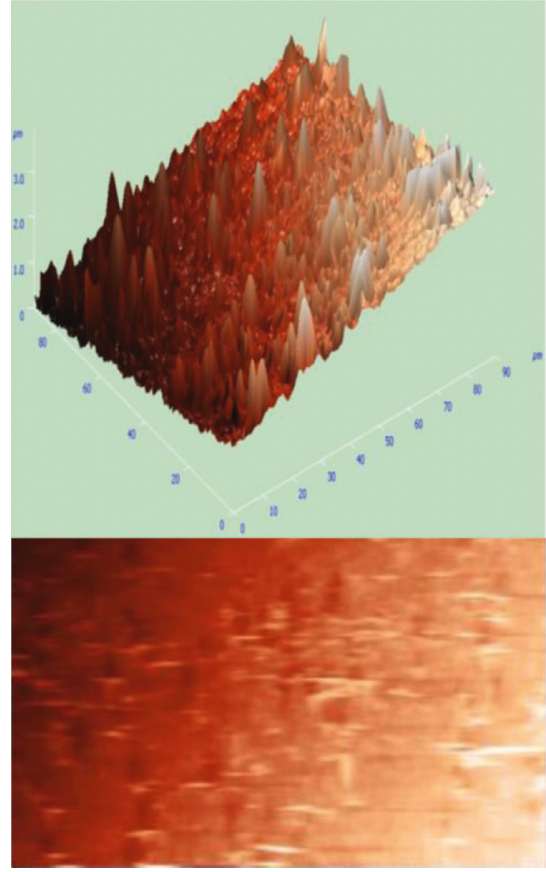

(b)
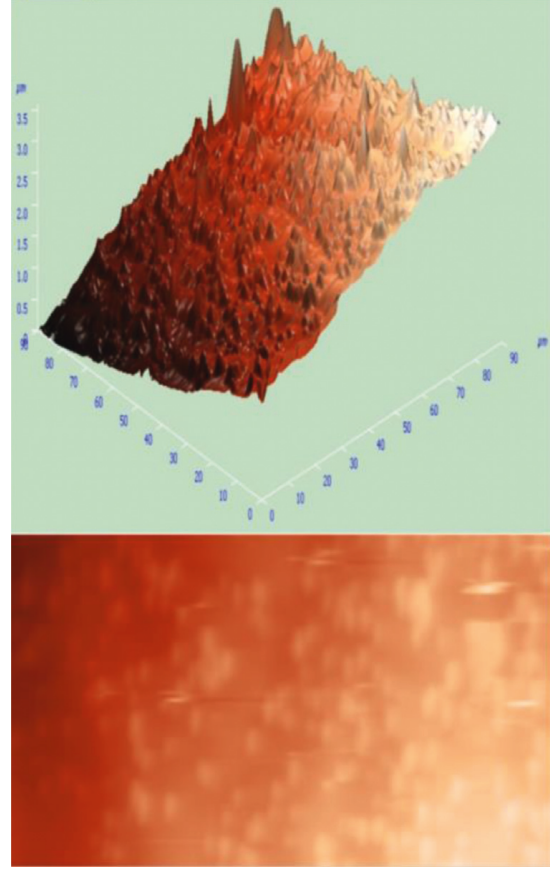

(c)

Figure 5: AFM images show the characteristic surface morphology form GCE (a); PtNFs/GCE deposited at the potential of $-0.2 \mathrm{~V}$ (b); $0.2 \mathrm{~V}$ (c).

roughness and which consequently leads to an increase of electrochemically active surface area of the electrode. This result will be reaffirmed in the next section.

3.3. Electrochemical Characterization of PtNFs/GCE. Electrochemical characterization of $\mathrm{Pt} / \mathrm{GC}$ electrodes prepared at different electrodeposition potentials of $-0.5 \mathrm{~V}$, $-0.3 \mathrm{~V},-0.2 \mathrm{~V}, 0.0 \mathrm{~V}$, and $0.2 \mathrm{~V}$ was carried out by cyclic voltammetry in two solutions which are $0.5 \mathrm{M} \cdot \mathrm{H}_{2} \mathrm{SO}_{4}$ and $5 \mathrm{mM} \mathrm{K}_{3}[\mathrm{Fe}(\mathrm{CN})]_{6}$. The electrochemically active surface areas of electrodes are calculated from the charge of hydrogen desorption peaks in $0.5 \mathrm{M} \cdot \mathrm{H}_{2} \mathrm{SO}_{4}$ solution and $\left[\mathrm{Fe}(\mathrm{CN})_{6}\right]^{3-}$ reduction peaks in $\mathrm{K}_{3} \mathrm{Fe}(\mathrm{CN})_{6}$ solution through Randles-Sevcik equation [29-31]. As can be seen from the obtained results (Figure 6), the variation of surface areas of Pt electrodes estimated from both methods vs. deposition potential has the same trend in general. However, the data 


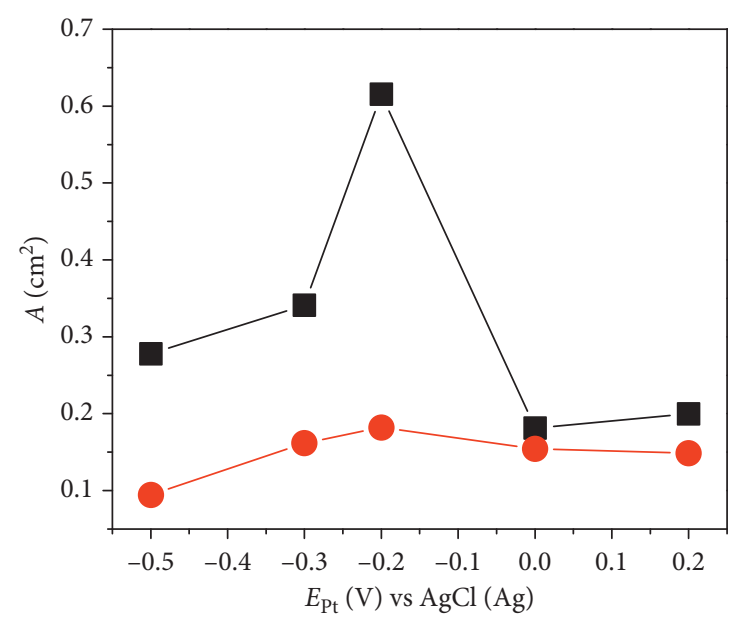

Figure 6: Effect of Pt electrodeposition potential on active surface area obtained from hydrogen desorption peaks (- $\square-)$ and ferricyanide reduction peaks (-๑).

calculated from hydrogen desorption peaks are higher than that obtained from ferricyanide reduction peaks. This could be explained by the fact that the size of the hydrogen atom is much smaller than that of the ferricyanide complex. As a result, the number of hydrogen is higher than the number of ferricyanide on the same electrode surface, especially on the Pt electrodes having a complex structure (flower-shaped nanostructure) that were prepared at $-0.2 \mathrm{~V},-0.3 \mathrm{~V}$, and $-0.5 \mathrm{~V}$. Obviously, surface areas calculated from charge of hydrogen desorption as well as from the ferricyanide peak current are directly proportional to the number of active species on the surface. Therefore, the surface areas of Pt electrodes calculated from the former method are higher than those obtained from the latter one. The data reveal that the largest area is reached at $-0.2 \mathrm{~V}$ of electrodeposition potential for both methods.

\subsection{Effect of Pt Electrodeposition Potential on Cadmium and} Lead Signals. As mentioned above, Pt deposition potential had a significant influence on the surface structure as well as the active surface area of the electrodes. Therefore, it certainly affects the electrochemical signal of cadmium and lead on these modified electrodes. Figure 7 shows DPASVs using GCE and the modified electrodes prepared at different electrodeposition potentials $(\mathrm{EPt})$ in acetate buffer solution $\mathrm{pH} 4.5$ containing $10 \mu \mathrm{g} \cdot \mathrm{L}^{-1} \cdot \mathrm{Pb}^{2+}$ and $\mathrm{Cd}^{2+}$. The higher peak signal on the PtNFs/GCE compared with the one on the GCE confirms the ability to detect cadmium and lead of the modified electrodes with higher sensitivity. It is observed that the peak height raises as $E_{\mathrm{Pt}}$ decreases and reaches a peak at $E_{\mathrm{Pt}}$ of $-0.2 \mathrm{~V}$, suggesting the amount of $\mathrm{Pb}^{2+}$ and $\mathrm{Cd}^{2+}$ preconcentrated onto the $\mathrm{Pt} / \mathrm{GCE}$ depends on the surface morphology of this modified electrode. At more negative electrodeposition potential, the surface area of the electrode significantly decreases. This can be explained by the fact that the stronger generation of hydrogen at lower potential can damage the aggregation of metal crystals [32]. In addition, the formation of larger hydrogen bubble prevented the deposition of $\mathrm{Pt}$ on the electrode surface, resulting in the exposure of large areas of GC substrate which can be clearly observed on the SEM image.

3.5. Repeatability, Reproducibility, and Selectivity of PtNFs/ $G C E$. In this section, the repeatability, reproducibility, and selectivity of the PtNFs/GCE were studied. The repeatability of the modified electrode was evaluated by measuring the $\mathrm{Pb}^{2+}$ and $\mathrm{Cd}^{2+}\left(10 \mu \mathrm{g} \cdot \mathrm{L}^{-1}\right)$, respectively, in acetate buffer $(\mathrm{pH}$ 4.5 ) at the same electrode (Figure 8(a)). The relative standard deviation (RSD) values were calculated to investigate the repeatability of the PtNFs/GCE as $1.59 \%$ for $\mathrm{Cd}^{2+}$ and $1.45 \%$ for $\mathrm{Pb}^{2+}$, showing the good stability of cadmium and lead signal at the electrode. The reproducibility of the PtNFs/GCE was calculated through the $\mathrm{Pb}^{2+}$ and $\mathrm{Cd}^{2+}\left(10 \mu \mathrm{g} \cdot \mathrm{L}^{-1}\right)$ signals from measurements of five different electrodes (Figure 8(b)). The RSD value of reproducibility was calculated to be $4.36 \%$ for $\mathrm{Cd}^{2+}$ and $4.65 \%$ for $\mathrm{Pb}^{2+}$ indicating that the fabrication procedure was reliable.

In order to evaluate the selectivity of the modified electrode, some common interferences were tested under optimized conditions. The effects of $\mathrm{Cu}^{2+}, \mathrm{Zn}^{2+}$, and $\mathrm{Fe}^{3+}$ were studied by recording the stripping peak current of $20 \mu \mathrm{g} \cdot \mathrm{L}^{-1} \cdot \mathrm{Pb}^{2+}$ and $\mathrm{Cd}^{2+}$ in the presence of interferences. The obtained results indicate that the presence of a 100 -fold excess of $\mathrm{Zn}^{2+}$ and $\mathrm{Fe}^{3+}$ does not influence the $\mathrm{Pb}^{2+}$ and $\mathrm{Cd}^{2+}$ signals. The interference of $\mathrm{Cu}^{2+}$ on the stripping peaks of $\mathrm{Pb}$ and $\mathrm{Cd}$ on the PtNFs/GCE was obtained even at $\mathrm{Cu}$ (II)-to$\mathrm{Pb}$ (II) or $\mathrm{Cu}(\mathrm{II})$-to- $\mathrm{Cd}(\mathrm{II})$ concentration ratios $10: 1$ and was more severe as the $\mathrm{Cu}(\mathrm{II})$-to-metal concentration ratio increased. In terms of the effects of organic compounds, especially surfactants could be absorbed on the electrode surface and so that they could influence the electrochemical responses of the $\mathrm{Pb}^{2+}$ and $\mathrm{Cd}^{2+}$ stripping peak current.

3.6. Calibration and Detection Limit. The linear range and detection limit were evaluated by using the optimal PtNFs/ GCE in acetate buffer solution ( $\mathrm{pH}$ 4.5). The DPASVs of increased amounts of metal ion species in the 


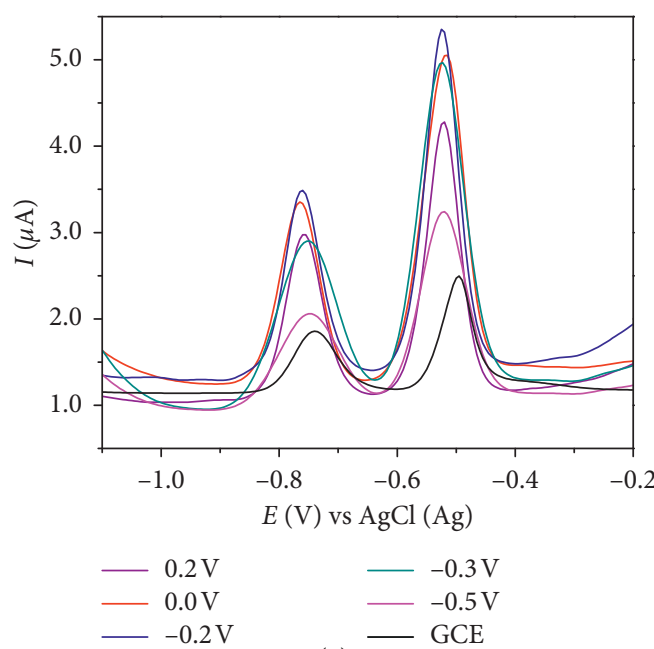

(a)

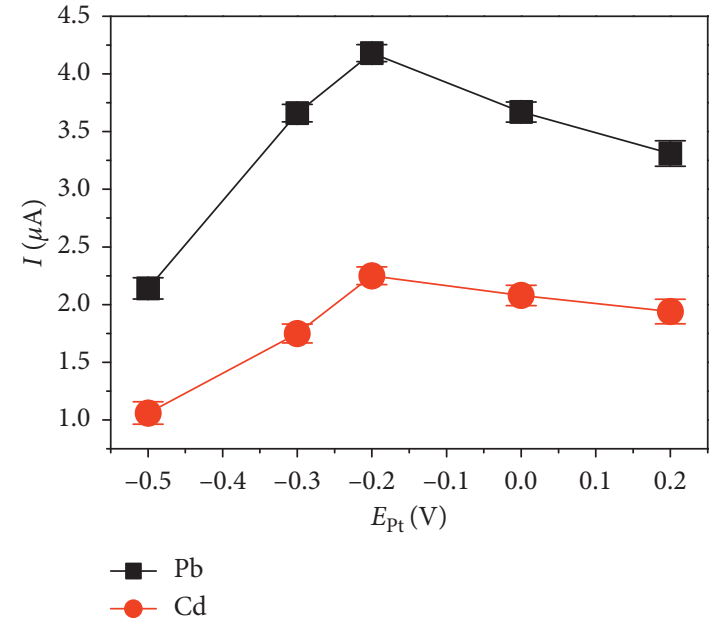

(b)

FIGURE 7: DPASVs at GCE and PtNFs/GCE prepared at different electrodeposition potentials (EPt) in acetate buffer solution pH 4.5 containing $10 \mu \mathrm{g} \cdot \mathrm{L}^{-1} \cdot \mathrm{Pb}^{2+}$ and $\mathrm{Cd}^{2+}(\mathrm{a})$; the influence of EPt of electrode fabrication on peak current of $\mathrm{Pb}^{2+}$ and $\mathrm{Cd}^{2+}(\mathrm{b})$.

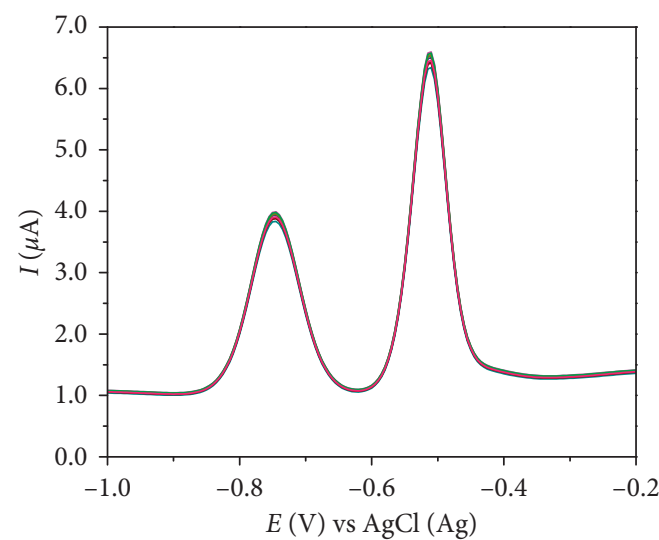

(a)
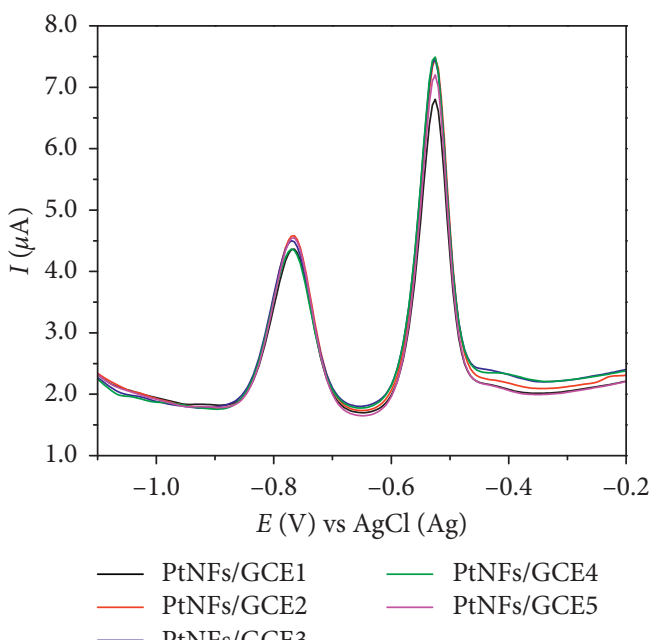

(b)

Figure 8: The DPASVs of $10 \mu \mathrm{g} \cdot \mathrm{L}^{-1} \cdot \mathrm{Pb}^{2+}$ and $\mathrm{Cd}^{2+}$ in acetate buffer ( $\mathrm{pH}$ 4.5) at one PtNFs/GCE with ten successive measurements (a) and at five different electrodes (b).

concentration range of $1-100 \mu \mathrm{g} \cdot \mathrm{L}^{-1}$ are illustrated in Figure 9(a). The corresponding calibration curves are shown in Figures 9(b) and 9(c) for lead and cadmium ions, respectively. Each point on these curves is an averaged value of three repeated measurements. The correlation equations were $\mathrm{I}=(1.754 \pm 0.479)+(0.366 \pm 0.0095) \mathrm{C}$ with a correlation coefficient of 0.998 for $\mathrm{Pb}^{2+}$ and $\mathrm{I}=(0.463 \pm 0.302)+(0.203 \pm 0.006) \mathrm{C}$ with a correlation coefficient of 0.997 for $\mathrm{Cd}^{2+}$, where $\mathrm{C}$ is the concentration of metal ions $\left(\mu \mathrm{g} \cdot \mathrm{L}^{-1}\right)$ and I is the peak current $(\mu \mathrm{A})$. The detection limits of 0.408 and $0.453 \mu \mathrm{g} \cdot \mathrm{L}^{-1}$ of $\mathrm{Pb}^{2+}$ and $\mathrm{Cd}^{2+}$ were estimated from 10 replicate determination of blank solution under optimum conditions, respectively. The comparison results of the proposed sensor with previously reported voltammetric procedures for lead and cadmium ions determination are presented in Table 1. This compares the sensing characteristics such as the linear range and the detection limit of some developed platforms based on different modified electrode materials. The limit of detection (LOD) of this our electrode is much lower than that of some sensors reported in Table 1. The results confirm that the proposed sensor had an acceptable utility for the simultaneous detection of $\mathrm{Pb}^{2+}$ and $\mathrm{Cd}^{2+}$ with high sensitivity and accuracy, low cost, and fast and simple operation.

\section{Conclusions}

Electrodeposition of platinum nanoflowers on GC electrodes was achieved by controlling the electrochemical 


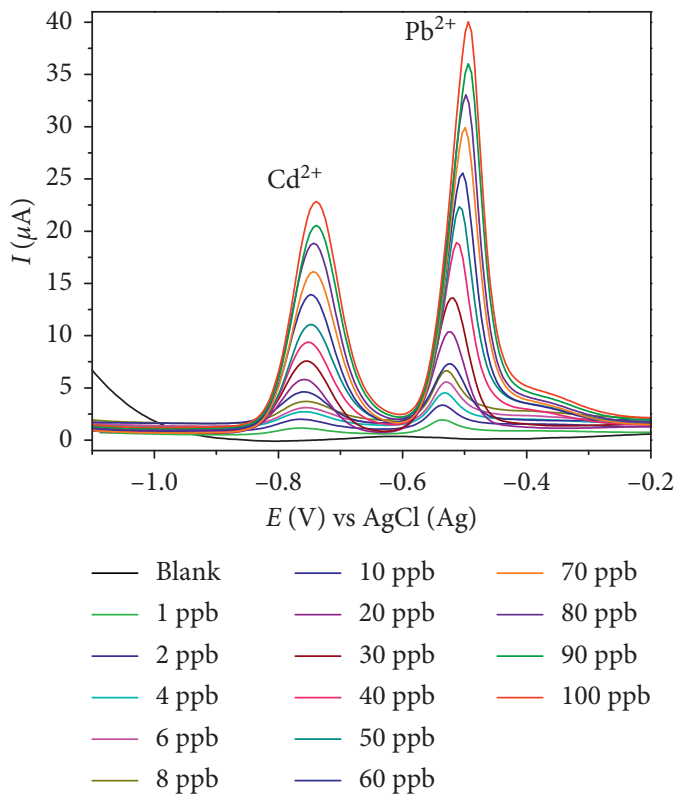

(a)

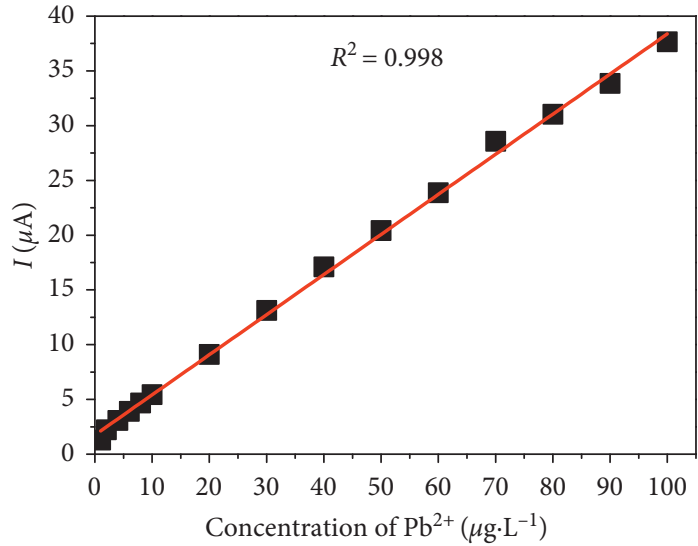

(b)

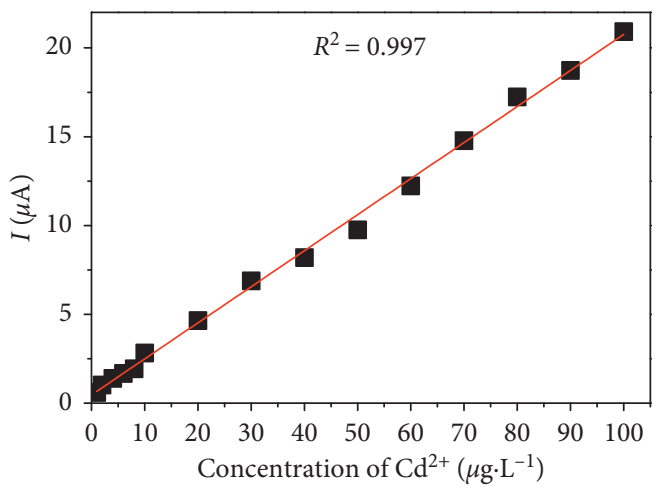

(c)

Figure 9: DPASVs at different concentrations of $\mathrm{Pb}^{2+}$ and $\mathrm{Cd}^{2+}$ ions at the PtNFs/GCE (a) and relationship between $\mathrm{Pb}^{2+}$ and $\mathrm{Cd}^{2+}$ concentrations with corresponding peak currents $(b, c)$.

TABLE 1: Comparison of the proposed sensor with other reported methods.

\begin{tabular}{|c|c|c|c|c|c|}
\hline \multirow{2}{*}{ Electrodes } & \multicolumn{2}{|c|}{ Linear range $\left(\mu \mathrm{g} \cdot \mathrm{L}^{-1}\right)$} & \multicolumn{2}{|c|}{ Detection limit $\left(\mu \mathrm{g} \cdot \mathrm{L}^{-1}\right)$} & \multirow{2}{*}{ Reference } \\
\hline & $\mathrm{Pb}^{2+}$ & $\mathrm{Cd}^{2+}$ & $\mathrm{Pb}^{2+}$ & $\mathrm{Cd}^{2+}$ & \\
\hline $\mathrm{ZnFe}_{2} \mathrm{O}_{4} / \mathrm{GCE}$ & $10-130$ & $10-130$ & 0.6 & 1.3 & {$[33]$} \\
\hline Polyaniline/GCE & $0-414$ & $0-224$ & 20.7 & 14.6 & {$[34]$} \\
\hline CB-15-crown-5/GCE & $10.9-186.5$ & $15.7-191.1$ & 3.3 & 4.7 & [35] \\
\hline $\mathrm{GSH} @ \mathrm{Fe}_{3} \mathrm{O}_{4}$ & $0.5-100$ & $0.5-100$ & 0.2 & 0.2 & {$[1]$} \\
\hline Sb-BDDE & $50-500$ & $100-500$ & 25.4 & 38.1 & [36] \\
\hline PtNFs/GCE & $1-100$ & $1-100$ & 0.4 & 0.5 & This work \\
\hline
\end{tabular}

GCE: glassy carbon electrode; CB-15-crown-5: 4-carboxybenzo-15-crown-5; GSH@Fe $\mathrm{O}_{4}$ : glutathione functionalized magnetic nanocomposite; $\mathrm{Sb}$-BDDE: antimony nanoparticle-modified boron-doped diamond electrode.

deposition time and potential. Our results show that the total active surface area of $\mathrm{Pt}$, as well as density and surface construction, can be controlled by adjusting deposition conditions. The composition and the microstructure of the modified PtNFs/GCE were characterized by XRD, EDX, SEM, and AFM techniques. Application of PtNFs/GCEs for the simultaneous electrochemical determination of $\mathrm{Pb}^{2+}$ and $\mathrm{Cd}^{2+}$ is reported for the first time. The proposed sensor showed good analytical signal response and exhibited very low detection limits of 0.408 and $0.453 \mu \mathrm{g} \cdot \mathrm{L}^{-1}$ for $\mathrm{Pb}^{2+}$ and $\mathrm{Cd}^{2+}$, respectively. The RSD of reproducibility of the PtNFs/ GCE of $4.36 \%$ for $\mathrm{Cd}^{2+}$ and $4.65 \%$ for $\mathrm{Pb}^{2+}$ demonstrated 
that the PtNFs/GCE is stable in sensing $\mathrm{Cd}^{2+}$ and $\mathrm{Pb}^{2+}$ and the procedure of preparation of PtNFs/GCE is reliable.

\section{Data Availability}

The data used to support the findings of this study are available from the corresponding author upon request.

\section{Conflicts of Interest}

The authors declare that there are no conflicts of interest regarding the publication of this paper.

\section{Acknowledgments}

This work was financially supported by Quy Nhon University, Vietnam, under grant no. T2018.557.06.

\section{Supplementary Materials}

Platinum nanoflowers modified glassy carbon electrodes (PtNFs/GCE) was prepared by electrodeposition. The modified electrodes have been characterized by EDX, SEM and AFM techniques to confirm chemical and physical properties. The electrochemical properties of PtNFs/GCE were investigated by cyclic voltammetry method $(\mathrm{CV})$. Application of PtNFs/GCE for the simultaneous electrochemical determination of $\mathrm{Pb}$ and $\mathrm{Cd}$ were performed by anodic stripping voltammetry method (ASV). (Supplementary Materials)

\section{References}

[1] M. Baghayeri, A. Amiri, B. Maleki, Z. Alizadeh, and O. Reiser, "A simple approach for simultaneous detection of cadmiu$\mathrm{m}$ (II) and lead(II) based on glutathione coated magnetic nanoparticles as a highly selective electrochemical probe," Sensors and Actuators B: Chemical, vol. 273, pp. 1442-1450, 2018.

[2] A. Kawde, A. Ismail, A. R. Al-betar, and O. Muraza, "Microporous and mesoporous materials novel ce-incorporated zeolite modified-carbon paste electrode for simultaneous trace electroanalysis of lead and cadmium," Microporous and Mesoporous Materials, vol. 243, pp. 1-8, 2017.

[3] J. E. L. Villa, R. R. A. Peixoto, and S. Cadore, "Cadmium and lead in chocolates commercialized in Brazil," Journal of Agricultural and Food Chemistry, vol. 62, no. 34, pp. 8759-8763, 2014.

[4] H. Needleman, "Lead poisoning," Annual Review of Medicine, vol. 55, no. 1, pp. 209-222, 2004.

[5] K. N. Dietrich, O. G. Berger, P. A. Succop, P. B. Hammond, and R. L. Bornschein, "The developmental consequences of low to moderate prenatal and postnatal lead exposure: intellectual attainment in the cincinnati lead study cohort following school entry," Neurotoxicology and Teratology, vol. 15, no. 1, pp. 37-44, 1993.

[6] D.-D. La, C. K. Kim, T. S. Jun et al., "Pt nanoparticlesupported multiwall carbon nanotube electrodes for amperometric hydrogen detection," Sensors and Actuators B: Chemical, vol. 155, no. 1, pp. 191-198, 2011.

[7] B. C. Han, C. R. Miranda, and G. Ceder, "Effect of particle size and surface structure on adsorption of $\mathrm{O}$ and $\mathrm{OH}$ on platinum nanoparticles: a first-principles study," Physical Review B, vol. 77, article 075410, pp. 1-9, 2008.

[8] V. Komanicky, H. Iddir, K.-C. Chang et al., "Fabrication and characterization of platinum nanoparticle arrays of controlled size, shape and orientation," Electrochimica Acta, vol. 55, no. 27, pp. 7934-7938, 2010.

[9] T. Bru, "Catalytic activity of platinum nanoparticles on highly boron-doped and 100-oriented epitaxial diamond towards HER and HOR," Physical Chemistry Chemical Physics, vol. 13, no. 28, pp. 12883-12891, 2011.

[10] E. Society and K. Kinoshita, "Particle size effects for oxygen reduction on highly dispersed platinum in acid electrolytes," Journal of Electrochemical Society, vol. 137, no. 3, pp. 845-848, 1990.

[11] J. Clausmeyer and W. Schuhmann, "Nanoelectrodes: applications in electrocatalysis, single-cell analysis and highresolution electrochemical imaging," TrAC Trends in Analytical Chemistry, vol. 79, pp. 46-59, 2016.

[12] L. Su, W. Jia, L. Zhang, C. Beacham, H. Zhang, and Y. Lei, "Facile synthesis of a platinum nanoflower monolayer on a single-walled carbon nanotube membrane and its application in glucose detection," Journal of Physical Chemistry C, vol. 114, no. 42, pp. 18121-18125, 2010.

[13] Y.-J. Lee and J.-Y. Park, "Nonenzymatic free-cholesterol detection via a modified highly sensitive macroporous gold electrode with platinum nanoparticles," Biosensors and Bioelectronics, vol. 26, no. 4, pp. 1353-1358, 2010.

[14] X. Wang, L. Li, Z. Li, J. Wang, H. Fu, and Z. Chen, "Determination of ascorbic acid in individual liver cancer cells by capillary electrophoresis with a platinum nanoparticles modified electrode," Journal of Electroanalytical Chemistry, vol. 712, pp. 139-145, 2014.

[15] Z. Dursun and B. Gelmez, "Simultaneous determination of ascorbic acid, dopamine and uric acid at Pt nanoparticles decorated multiwall carbon nanotubes modified GCE," Electroanalysis, vol. 22, no. 10, pp. 1106-1114, 2010.

[16] M. Doulache, N. K. Bakirhan, B. Uslu, B. Saidat, M. Trari, and S. A. Ozkan, "Simple and sensitive adsorptive stripping voltammetric assay of granisetron from its dosage form by platinum nanoparticles modified electrodes," Sensors and Actuators B: Chemical, vol. 251, pp. 572-582, 2017.

[17] J.-H. Yoon, G. Muthuraman, J. Yang, Y.-B. Shim, and M.-S. Won, "Pt-nanoparticle incorporated carbon paste electrode for the determination of $\mathrm{Cu}$ (II) ion by anodic stripping voltammetry," Electroanalysis, vol. 19, no. 11, pp. 1160-1166, 2007.

[18] N. Tian, Z. Zhou, S. Sun, L. Cui, B. Ren, and Z. Tian, "Electrochemical preparation of platinum nano thorn assemblies Raman scattering activity with high surface enhanced," Chemical Communications, vol. 39, no. 39, pp. 4090-4092, 2006.

[19] X. Chen, B. Su, G. Wu et al., "Platinum nanoflowers supported on graphene oxide nanosheets: their green synthesis, growth mechanism, and advanced electrocatalytic properties for methanol oxidation," Journal of Materials Chemistry, vol. 22, no. 22, pp. 11284-11289, 2012.

[20] Y. Zhang, Z. Shao, Q. Shen, M. Li, L. Xu, and Z. Luo, "Aqueous preparation of platinum nanoflowers on threedimensional graphene for efficient methanol oxidation," Catalysts, vol. 8, no. 11, p. 519, 2018.

[21] R.-X. Wang, J.-J. Fan, Y.-J. Fan et al., "Platinum nanoparticles on porphyrin functionalized graphene nanosheets as a superior catalyst for methanol electrooxidation," Nanoscale, vol. 6, no. 24, pp. 14999-15007, 2014. 
[22] G. A. El-Nagar, A. M. Mohammad, and M. S. El-deab, "Acrylonitrile-contamination induced enhancement of formic acid electro-oxidation at platinum nanoparticles modified glassy carbon electrodes," Journal of Power Sources, vol. 265, pp. 57-61, 2014.

[23] A. Tabet-Aoul and M. Mohamedi, "Interrelated functionalities of hierarchically $\mathrm{CNT} / \mathrm{CeO}_{2} / \mathrm{Pt}$ nanostructured layers: synthesis, characterization, and electroactivity," Physical Chemistry Chemical Physics, vol. 14, no. 13, p. 4463, 2012.

[24] S. V. Doronin, R. A. Manzhos, A. G. Krivenko, and A. P. Manzhos, "Electron transfer kinetics of the ferrous/ferric redox system on the platinum deposits on gold," Journal of Electroanalytical Chemistry, vol. 784, pp. 140-144, 2017.

[25] P. K. Kalambate and A. K. Srivastava, "Simultaneous voltammetric determination of paracetamol, cetirizine and phenylephrine using a multiwalled carbon nanotube-platinum nanoparticles nanocomposite modified carbon paste electrode," Sensors and Actuators B: Chemical, vol. 233, pp. 237-248, 2016.

[26] S. Kim, Y. Jung, and S.-J. Park, "Catalytic activity of electrically deposited platinum nanoparticle catalysts on graphite nanofibers," Colloids and Surfaces A: Physicochemical and Engineering Aspects, vol. 313-314, pp. 220-223, 2008.

[27] E. Proniewicz, B. Gralec, T. K. Olszewski, and B. Boduszek, "Aqueous platinum nanoparticles solution for the detection of pyridine derivatives of aminophosphinic acid. Influence of positional isomerism," Applied Surface Science, vol. 425, pp. 941-947, 2017.

[28] A. Kumaravel and M. Chandrasekaran, "Nanosilver/ surfactant modified glassy carbon electrode for the sensing of thiamethoxam," Sensors and Actuators B: Chemical, vol. 174, pp. 380-388, 2012.

[29] J. Wang, Analytical Electrochemistry, John Wiley \& Sons, New York, NY, USA, 43rd edition, 2006.

[30] A. Gamero-quijano, F. Huerta, D. Salinas-torres, E. Morallón, and F. Montilla, "Electrocatalytic performance of $\mathrm{SiO}_{2}{ }^{-}$ SWCNT nanocomposites prepared by electroassisted deposition," Electrocatalysis, vol. 4, no. 4, pp. 259-266, 2013.

[31] T. N. Huan, T. Ganesh, K. S. Kim, S. Kim, S.-H. Han, and H. Chung, "A three-dimensional gold nanodendrite network porous structure and its application for an electrochemical sensing," Biosensors and Bioelectronics, vol. 27, no. 1, pp. 183-186, 2011.

[32] I. Švancara, C. Prior, S. B. Hočevar, and J. Wang, "A decade with bismuth-based electrodes in electroanalysis," Electroanalysis, vol. 22, no. 13, pp. 1405-1420, 2010.

[33] N. S. Arun Kumar, S. Ashoka, and P. Malingappa, "Nano zinc ferrite modified electrode as a novel electrochemical sensing platform in simultaneous measurement of trace level lead and cadmium," Journal of Environmental Chemical Engineering, vol. 6, no. 6, 2018.

[34] Z. Wang, E. Liu, and X. Zhao, "Glassy carbon electrode modified by conductive polyaniline coating for determination of trace lead and cadmium ions in acetate buffer solution," Thin Solid Films, vol. 519, no. 15, pp. 5285-5289, 2011.

[35] N. Serrano, A. González-Calabuig, and M. del Valle, "Crown ether-modified electrodes for the simultaneous stripping voltammetric determination of $\mathrm{Cd}(\mathrm{II}), \mathrm{Pb}(\mathrm{II})$ and $\mathrm{Cu}(\mathrm{II})$," Talanta, vol. 138, pp. 130-137, 2015.

[36] K. E. Toghill, L. Xiao, G. G. Wildgoose, and R. G. Compton, "Electroanalytical determination of cadmium(II) and lead(II) using an antimony nanoparticle modified boron-doped diamond electrode," Electroanalysis, vol. 21, no. 10, pp. 11131118, 2009. 

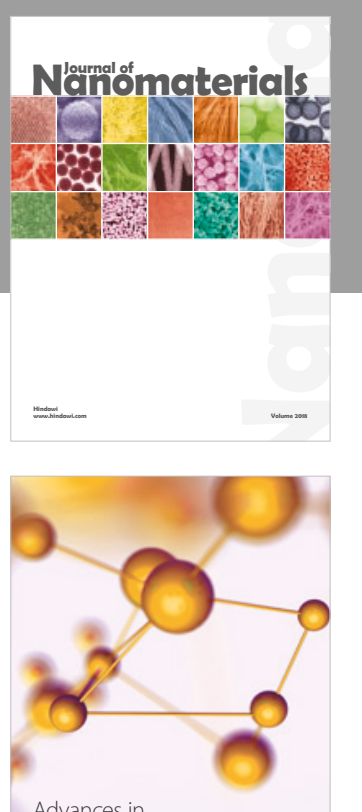

Physical Chemistry
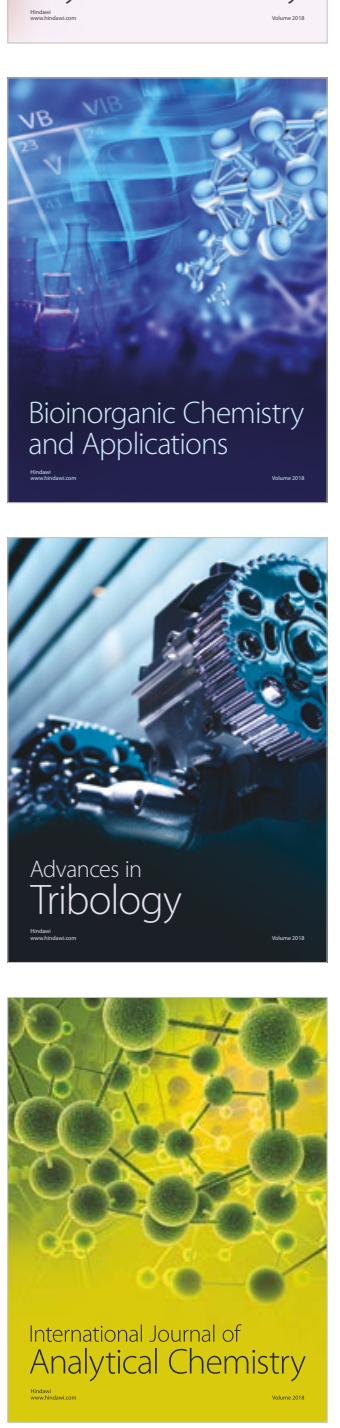

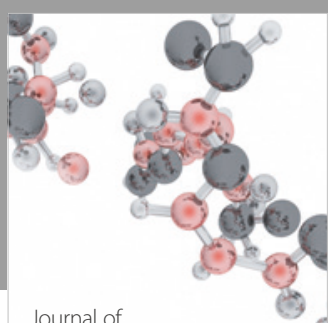

Analytical Methods

in Chemistry

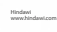

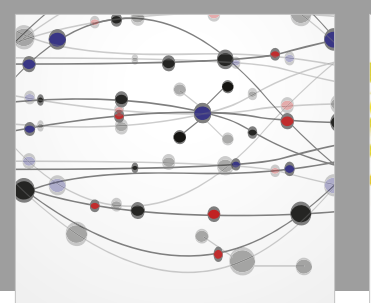

The Scientific World Journal

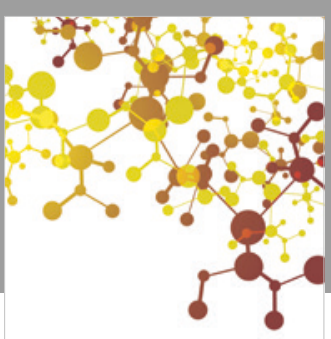

Journal of

Applied Chemistry
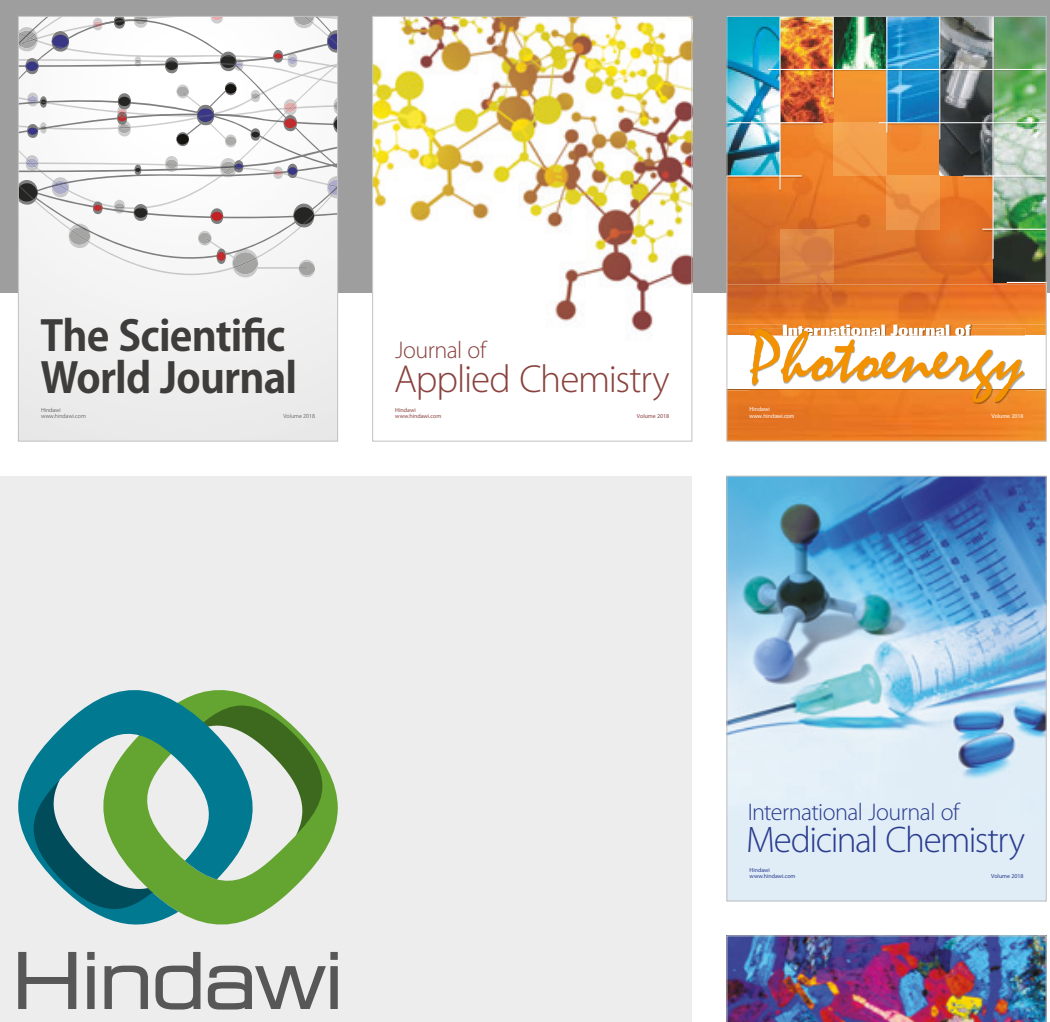

Submit your manuscripts at

www.hindawi.com
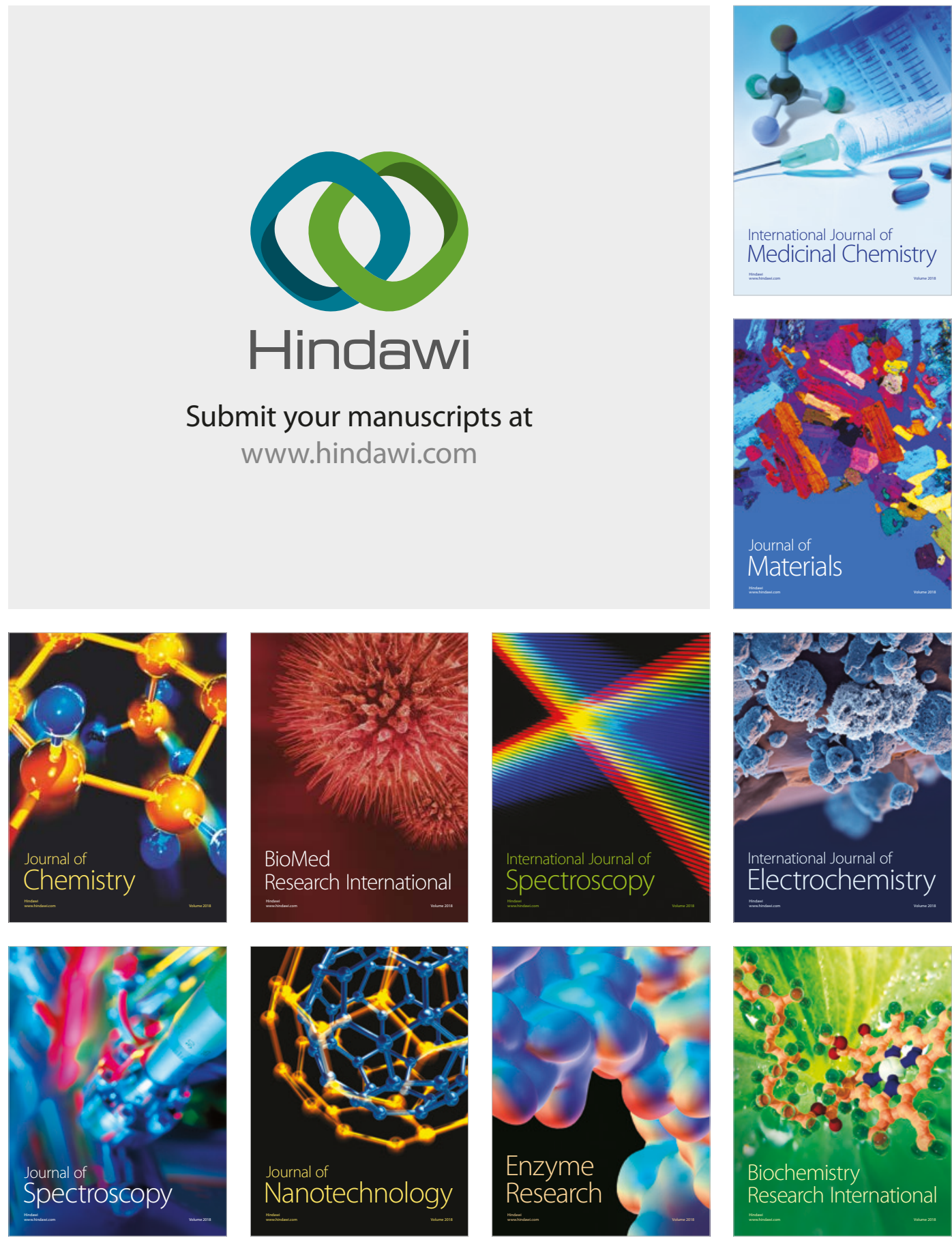
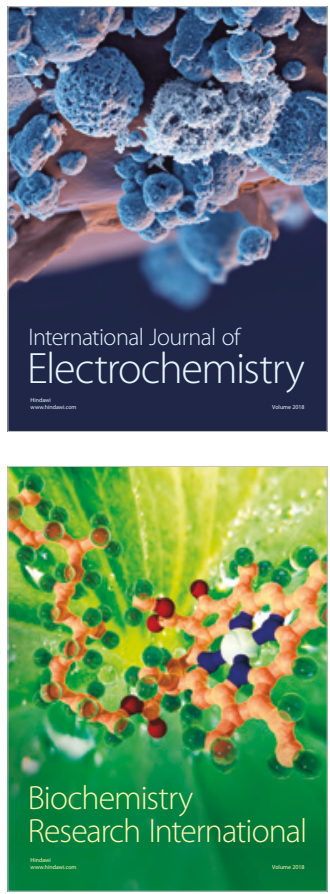